\title{
The Influence of Filtration of Atrasine on the Spectrum of Positron Lifetimes in Immobilized Liquid Filtration Membranes
}

\author{
R. Pietrzak*, E. Maksymiuk \\ Institute of Physics, Opole University, Oleska 48, 45-052 Opole, Poland
}

AND A. KAJDAS

M. Skłodowska-Curie Institute - Centre of Oncology

Wybrzeże Armii Krajowej 15, 44-101 Gliwice, Poland

The spectra of positron lifetimes were investigated in elements which were later used to form an immobilized liquid membrane and also in the immobilized liquid membrane, after different times of atrasine filtration. Next, the spectra of positron lifetimes were separated out into three components. The values of the components of the positron lifetimes spectrum indicated the formation of the Ps-atom both in the elements composing the membrane and in the very membrane itself. An influence of the filtration time of atrasine on the values of all components of positron lifetimes spectrum was found. On the basis of Eldrup-Tao model, changes in the sizes of spherical free spaces in the membrane and relative free volume in which ortho-Ps annihilated were determined.

PACS numbers: $78.70 . \mathrm{Bj}, 46.70 . \mathrm{Hg}$

\section{Introduction}

Isolation, cleansing and distribution of forming products belong to the most significant processes made use of in the chemical industry, pharmacy and in sewage treatment plants. During chemical analyses it is often necessary to condense the products or, sometimes, to separate them. In medical applications, during microand ultra-filtration, or during dialysis (e.g. in artificial kidney, artificial lung) it is required to constantly monitor the content of aminoacids, in particular — peptides, as drugs. The content of pesticides in environment and in structural fluids also

*corresponding author; e-mail: pietr@uni.opole.pl 
requires constant monitoring. In order to attain the goals new techniques are searched for, one of them being the membrane technology. The membrane is understood as semi-permeable phase (generally very thin) which separates two other ones (liquid as well as gaseous). They act as passive or active barriers between which given substances are transported. In recent years liquid membranes containing a selective carrier have roused a great deal of interest. In membranes of this type the substance is transported from the donor phase to the acceptor one. There is a third phase between them - a liquid membrane. There exist a few types of immobilized liquid membrane (ILM), but in each of them the proper membrane is placed in pores of a thin porous polymer foil (Fig. 1). The processes of transportation in them, however, have not been known thoroughly yet. It can only be speculated that at the time of transportation of the substance through them there occur changes in their internal structure.

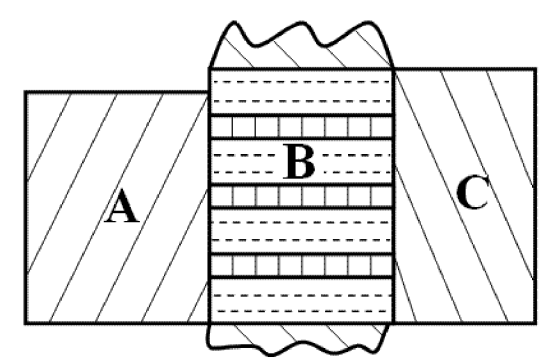

Fig. 1. A model of immobilized liquid membrane: A - donor (0.01 solution of atrasine), B - porous filtration paper "Fluoropore $0.2 \mu \mathrm{m}$ " soaked with dihexile ether, $\mathrm{C}$ - the acceptor (0.5 M solution of sulphuric acid).

For quite a few years now the technique of measurement of positron lifetimes has been used as an auxiliary method to investigate the microstructure of polymers, liquids and gels. In order to determine the sizes of free volumes in substances in which positronium forms (e.g. voids in gels and liquids) this technique was widely applied by Goworek et al. [1-7], Jerie et al. [8-12], Osoba [13-17] and others [18-20]. The theoretical relation between ortho-Ps and the dimensions of internal "voids", as offered by Tao [21] and Eldrup et al. [22], has been made use of in the present work.

The paper deals with investigation of positron lifetimes, separately, in elements forming an ILM at a later stage, as well as in the membrane before and after filtration of atrasine.

\section{Preparation of samples for investigations}

Positron lifetimes were determined, separately, in elements which formed, later on, an ILM and also in the membrane before and after 30, 100, and 180 minute long filtration of atrasine. The carrier of the ILM was filter paper 
"Fluoropore" of $115 \mu \mathrm{m}$ thickness, $0.2 \mu \mathrm{m}$ of pores diameter and $70 \%$ porosity. The membrane proper being dihexile ether immobilized in the pores of the carrier. The donor was $0.01 \mathrm{M}$ solution of atrasine, while the acceptor $-0.5 \mathrm{M}$ solution of sulphuric acid.

At the first stage of the investigation, parameters of the spectrum of positron lifetimes were determined in liquid dihexile ether. The ether filled up two broad plexiglass vessels $7 \mathrm{~mm}$ deep and $20 \mathrm{~mm}$ diameter which were tightly covered with hostaphanic foil of surface density $0.9 \mathrm{mg} / \mathrm{cm}^{2}$. Between them there was a source of ${ }^{22} \mathrm{Na}$ positrons also covered with hostaphanic foil (Fig. 2). At the next stage, annihilation of positrons was investigated in dry filter paper "Fluoropore $0.2 \mu \mathrm{m}$ ". Two piles of circles cut out of this foil (numbering 10 in each) were placed in similar plexiglass vessels which were used in investigations of annihilation in the dihexile ether. One end of these vessels was covered with the hostaphanic foil, whereas the other end had a moving tight plexiglass piston. They served the purpose of pressing the pile of filter papers so that the free space between the successive circles would be minimal (Fig. 3). Next, the positron lifetimes were determined in the filter paper soaked with dihexile ether during 1.5 hours. The geometry of measurement was similar to that in the investigations of "dry" filter paper.

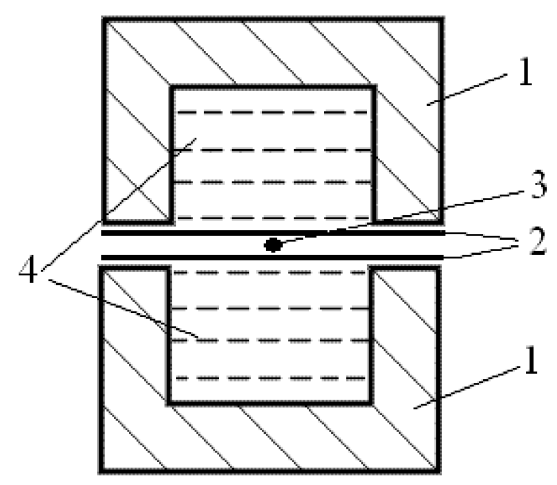

Fig. 2. A diagram of the apparatus to investigate annihilation of positrons in liquid dihexile ether: 1 - plexiglass vessels, 2 - hostaphanic foil, 3 - source of ${ }^{22}$ Na positrons, 4 - dihexile ether.

At the next stage of the investigation, the positron lifetimes were determined in the ILM after 30, 100, and 180 minutes of filtering it with atrasine. The filtration was carried out by means of a separator constructed at the Institute of Chemistry, Opole University. The separator was built from two blocks, cylindrical in their shape, made of ethylene polytetrafluoride (PTFE), with hollowed canals in the shape of spiral of Archimedes (0.25 mm thick, $1.5 \mathrm{~mm}$ wide and $2.5 \mathrm{~m}$ long) $1 \mathrm{~cm}^{3}$ in volume each (Fig. 4). The porous membrane impregnated with dihexile ether was placed between these blocks which were additionally compressed with 


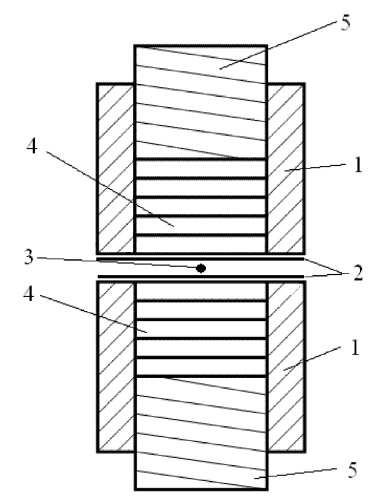

Fig. 3. The research set used to investigate positron annihilation in the "dry" filtration paper and in the immobilized liquid membrane: 1 - plexiglass vessels, 2 - hostaphanic foil, 3 - source of ${ }^{22} \mathrm{Na}$ positrons, 4 - a pile of filtration papers "dry" or soaked with dihexile ether, before and after filtration, 5 - tightening movable plexiglass pistons.

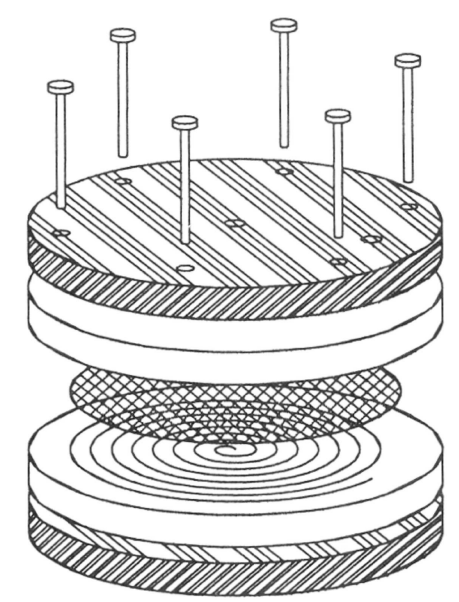

Fig. 4. The separator applied in extraction of chemical compounds.

two aluminum blocks, and the whole was integrated with eight screws. The filtered solution of atrasine was gravitationally pumped into it from one side of the membrane, while - on the other one - there was placed the acceptor. The latter was $0.5 \mathrm{M}$ solution of "dry" paper soaked with dihexile ether prior to the filtration. In order to determine the spectra of positron lifetimes in the investigated systems a fast-slow spectrometer of 250 ps resolution was used.

\section{Results of measurements}

The aim of the research was to determine the changes in the inner structure of ILM before and after three times of filtration of atrasine. The membrane was dihexile ether immobilized in filtration paper "Fluoropore $0.2 \mu \mathrm{m}$ ". 
At the first stage of the investigation the positron lifetimes spectrum was determined in liquid dihexile ether (bars A in Fig. 5), then in a pile of "dry" filtration papers (bars B) and in the one of filtration papers soaked with dihexile ether (bars C). We shall call the filtration paper soaked with dihexile ether "the ILM before filtration" further in the present paper (filtration time $t=0$ ).

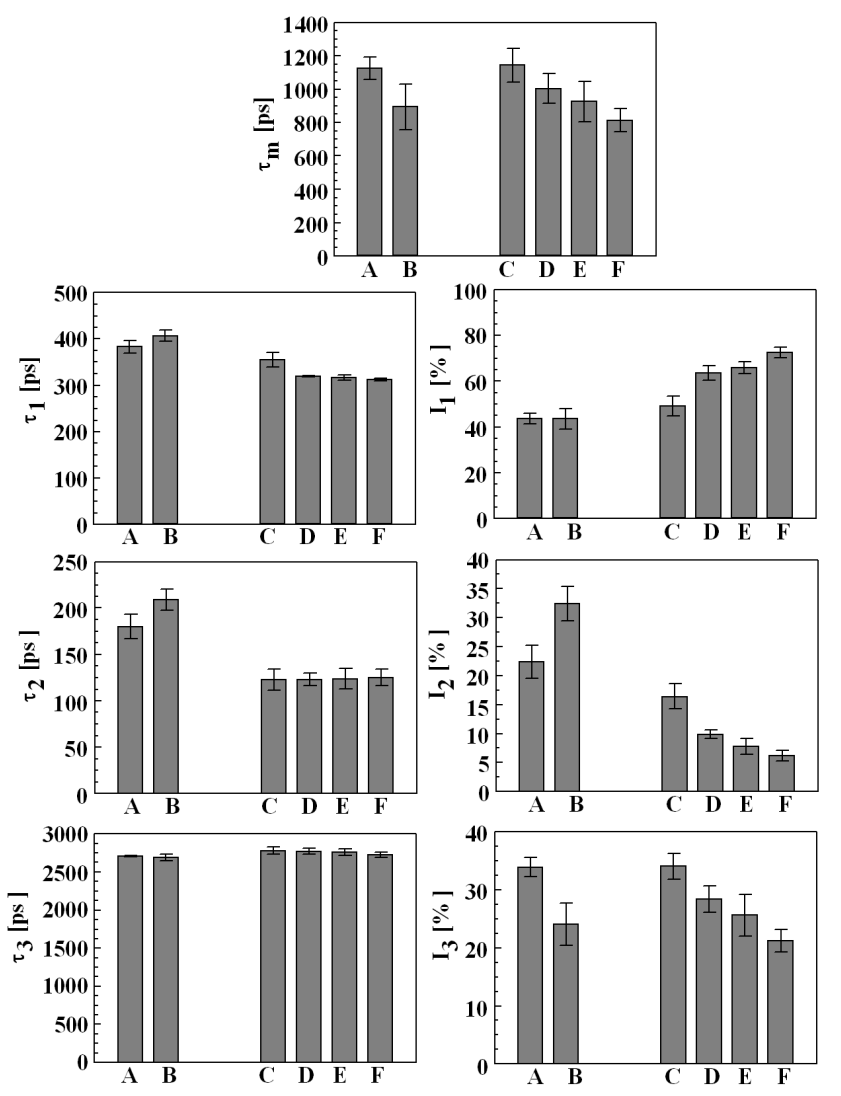

Fig. 5. Parameters of positron lifetimes spectra in liquid dihexile ether (bars A), in the pile of "dry" filtration papers (bars B), in the immobilized liquid membrane before filtration (bars C), in the immobilized liquid membrane after 30 minute filtration (bars D), after 100 minute filtration (bars E), and after 180 minute filtration (bars F).

Bars D, E, F in Fig. 5 correspond to the parameters of spectrum of positron lifetimes in the membrane through which atrasine was filtered during 30, 100, and 180 minutes, respectively, in the manner described in the previous part.

The obtained spectra of positron lifetimes were distributed into 2 or 3 components. When separating the spectrum into three components of lifetimes $\tau_{1}, \tau_{2}, \tau_{3}$ and intensities $I_{1}, I_{2}, I_{3}$, respectively, the adjustment coefficient $\chi^{2}$ was nearer one than in the case of the distribution into two components (1.088 and 1.107 
respectively). An analysis of the obtained results points to that in all the cases it was possible to isolate a component of lifetime of nanoseconds order, which testifies to positron annihilation in the pick-off process of ortho-Ps localized in the empty space of the material. The lifetime component determined by us as $\tau_{2}$ and intensity $I_{2}$ in the membrane falls within $122 \div 125 \mathrm{ps}$ and is interpreted as the result of annihilation of para-Ps. The spectrum component of indirect lifetime with the index 1 is attributed to annihilation of positrons in the free state.

For all the investigated systems the mean lifetime $\tau_{\mathrm{m}}$ was also determined by means of the following formula:

$$
\tau_{\mathrm{m}}=\frac{\sum_{i} \tau_{i} I_{i}}{\sum_{i} I_{i}} .
$$

As it can be seen in Fig. 5 the parameters $\tau_{i}$ and $I_{i}(i=1,2,3)$ for the constituents of the membrane are, within the limit of error, similar to one another (bars A and B).

A relatively big difference can be observed between the values of para-Ps lifetime $\left(\tau_{2}\right)$ in liquid dihexile ether and filtration membrane and the lifetime $\tau_{2}$ in membrane saturated with ether. We believe that in these two cases the component $\tau_{2}$ comes from the conversion of ortho-Ps into para-Ps. Most probably, filling the filtration membrane with ether partially closes this annihilation channel.

Much clearer differences between the parameters of lifetimes spectra can be observed in the immobilized membrane after different times of filtration of atrasine. The filtration time $t$ influences, in a visible way, the positron lifetimes both from the free state $\left(\tau_{1}\right.$ and $\left.I_{1}\right)$ and from the bounded state of para- $\left(\tau_{2}, I_{2}\right)$ and ortho-Ps $\left(\tau_{3}, I_{3}\right)$. As it can be seen in Fig. 5, prolongation of filtration time results in an increase in the number of annihilation acts and shortening of positron lifetimes in the free state.

The filtration time, however, does not influence in any visible manner the positron lifetime in the para state $(122 \div 125.2 \mathrm{ps})$, although the number of annihilation acts from this state clearly decreases along with the length of filtration time. On the other hand, the value of component $\tau_{3}$, corresponding to annihilation of ortho-Ps in the pick-off process decreases insignificantly (by about 1.8\%) after 180 minutes of filtration (Fig. 6). The intensity of this component, however, decreases considerably, by as much as $38 \%$. The obtained results prove that during penetration of atrasine into the acceptor soaked with dihexile ether there follows a worsening of the conditions of the Ps formation.

According to the model proposed by Tao [21] and Eldrup et al. [22], the component of the longest lifetime $\left(\tau_{3}\right)$ connected with annihilation of ortho-Ps in polymers and liquids is bounded with the mean radius of free volume $R$ by means of the relation

$$
\tau_{3}=\lambda_{0}\left[1-\frac{R}{R+\Delta R}+(2 \pi)^{-1} \sin \frac{2 \pi R}{R+\Delta R}\right]^{-1},
$$



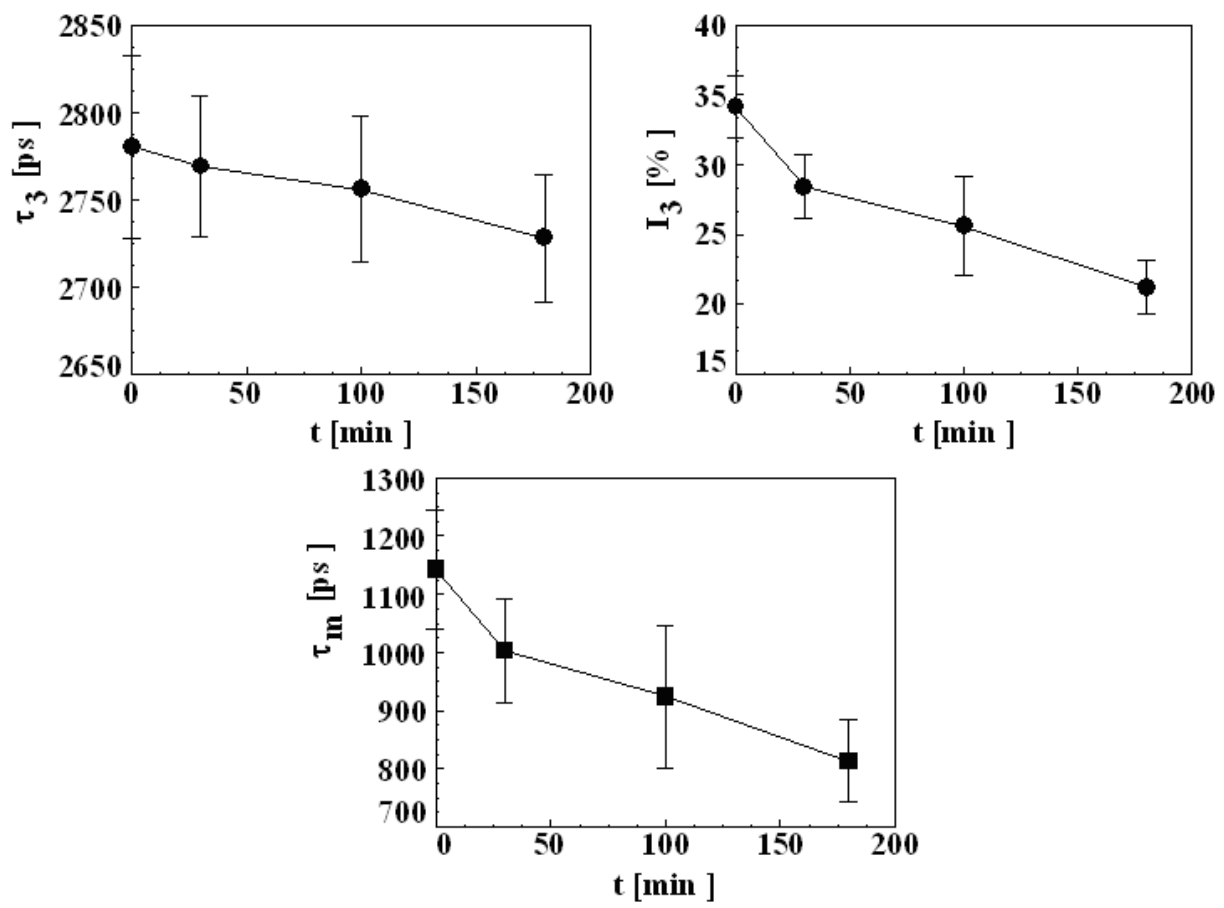

Fig. 6. The dependences of lifetimes $\left(\tau_{3}\right)$ and the intensity $\left(I_{3}\right)$ of ortho-Ps component and $\tau_{\mathrm{m}}$ on the time of filtration of atrasine in the immobilized liquid membrane.

where $\lambda_{0}^{-1}=0.5 \mathrm{~ns}, \Delta R=0.1656 \mathrm{~nm}, \Delta R$ is a certain constant dependent on the shape of free space, in which positron annihilates. For the spherical free space its value is commonly assumed as $0.1656 \mathrm{~nm}$.

Figure 7 presents the dependence of the radius of free volume (spherical) $R$ on filtration time $t$. It can be seen that within the examined time range the radius of the spherical "void" changes very insignificantly, merely by around $0.5 \%$ after 200 minutes of filtration.

Measurements of positron lifetimes, in systems in which positronium forms, allow to evaluate the so-called relative free volume $f$. This parameter is defined as follows:

$$
f=\frac{V-V_{0}}{V},
$$

where $V$ - the total macroscopic volume of the system, $V_{0}$ - volume occupied by molecules of the system.

Wang et al. [23] as well as Kobayashi et al. [24] proposed a semi-empirical equation which can be applied to assess the values of this parameter on the basis of annihilation parameters of the positron lifetimes spectrum

$$
f=A I_{3} \frac{4}{3} \pi R^{3}=A F
$$



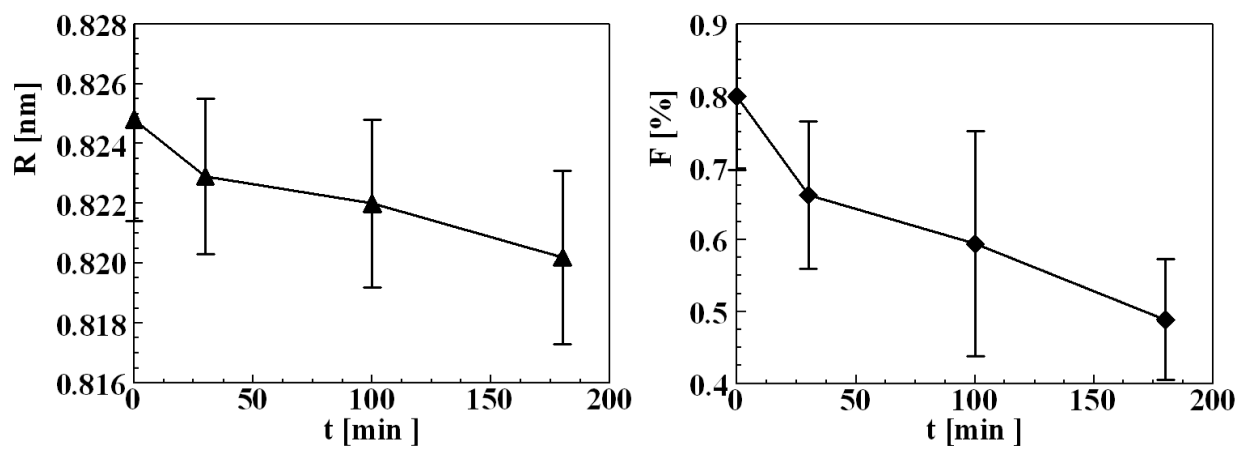

Fig. 7. The dependences of the mean radius of empty spherical volume in the membrane and parameter $F$ on the filtration time of atrasine.

where $F=I_{3} \frac{4}{3} \pi R^{3}, V_{0}=\frac{4}{3} \pi R^{3}$ is the volume of a single spherical defect in which ortho-Ps annihilates; $A$ - a normalizing constant. According to Wang et al. the value of this parameter at room temperature is close to unity.

Figure 7 shows also the dependence of parameter $F$ on filtration time $t$. It can be seen in the figure that after 180 minutes of filtration the value of this parameter decreases by almost $39 \%$.

The changes in the inner structure of the membrane that are reflected in the changes in the spectra of positron lifetimes can be induced by diffusion of atrasine from the donor phase into dihexile ether distributed in the pores of hydrophobic filtration membrane or, on the contrary, elution of the ether from the membrane into the acceptor phase. Anyway, in consequence, both processes lead to a rise in the concentration of atrasine in dihexile ether. A full explanation of these processes requires carrying out additional research both in the field of chemistry and positron annihilation.

\section{Conclusions}

The following conclusions can be formulated on the basis of the conducted investigations:

- the spectrum of positrons lifetime in the investigated ILM consists of three components, two of which correspond to annihilation of the positron from the Ps state;

- together with the rise in length of filtration time, there increases the contribution of annihilation from the free state and decreases the contribution of annihilation from the states of para- and ortho-Ps;

- the time of filtration of atrasine through the ILM only slightly shortens the radius of the empty sphere in which positron annihilates, while it visibly lowers the relative free volume available to positron. 


\section{References}

[1] K. Ciesielski, A.L. Dawidowicz, T. Goworek, Acta Phys. Pol. A 95, 483 (1999).

[2] T. Goworek, J. Nucl. Radiochem. Sci. 1, 11 (2000).

[3] T. Goworek, T. Suzuki, E. Hamada, K. Kondo, Y. Ito, Chem. Phys. 255, 347 (2000).

[4] B. Jasińska, A.L. Dawidowicz, S. Radkiewicz, Acta Phys. Pol. A 99, 379 (2001).

[5] B. Jasińska, A.L. Dawidowicz, in: Proc. 34th Polish Seminar on Positron Annihilation, Turawa (Poland) 2002, Ed. K. Jerie, University of Opole, University of Wrocław, Opole 2002, p. 39.

[6] T. Goworek, J. Wawryszczuk, R. Zaleski, Acta Phys. Pol. A 107, 608 (2005).

[7] T. Goworek, J. Wawryszczuk, R. Zaleski, Chem. Phys. Lett. 387, 433 (2004).

[8] A. Baranowski, M. Dȩbowska, K. Jerie, L. Kurzeja, K. Hennek, J. Rudzińska-Girulska, Acta Phys. Pol. A 88, 43 (1995).

[9] K. Jerie, A. Baranowski, J. Gliński, K. Orzechowski, Acta Phys. Pol. A 95, 562 (1999).

[10] K. Jerie, A. Baranowski, J. Gliński, K. Orzechowski, Acta Phys. Pol. A 95, 569 (1999).

[11] K. Jerie, A. Baranowski, J. Gliński, K. Orzechowski, J. Przybylski, Acta Phys. Pol. A 99, 393 (2001).

[12] K. Jerie, A. Baranowski, J. Przybylski, J. Gliński, in: Proc. 33rd Seminar on Positron Annihilation, Turawa (Poland) 2001, Ed. K. Jerie, University of Opole, University of Wrocław, Opole 2002, p. 51.

[13] W. Osoba, Acta Phys. Pol. A 95, 632 (1999).

[14] W. Osoba, Acta Phys. Pol. A 99, 447 (2001).

[15] J. Borek, W. Osoba, J. Polym. Sci. B, Polym. Phys. 34, 1903 (1996).

[16] A. Danch, W. Osoba, in: Proc. 33rd Seminar on Positron Annihilation, Turawa (Poland) 2001, Ed. K. Jerie, University of Opole, University of Wrocław, Opole 2002, p. 117.

[17] J. Borek, W. Osoba, Acta Phys. Pol. A 88, 117 (1995).

[18] K. Ito, Y. Ujihira, T. Yamashita, K. Horie, Acta Phys. Pol. A 95, 551 (1999).

[19] Zs. Kajcos, L. Liszkay, D. Duplatre, L. Varga, K. Lazar, G. Pal-Borbely, H.K. Berger, L. Lokonyai, C. Caullet, J. Patrin, Acta Phys. Pol. A 99, 399 (2001).

[20] T. Hirade, Acta Phys. Pol. A 107, 613 (2005).

[21] S. Tao, J. Chem. Phys. 56, 5499 (1972).

[22] M. Eldrup, D. Lightbody, J. Sherwod, J. Chem. Phys. 63, 51 (1981).

[23] Y. Wang, H. Nakanishi, Y. Jean, T. Sandreczki, J. Polym. Sci. B, Polym. Phys. 28, 143 (1990).

[24] Y. Kobayashi, W. Zeng, E. Meyer, J. Mc Gervey, A. Jemison, R. Simha, Macromolecules 22, 2302 (1989). 